\title{
Why are South Asians prone to type 2 diabetes? A hypothesis based on underexplored pathways
}

\author{
K. M. Venkat Narayan ${ }^{1,2}$ (D) Alka M. Kanaya $^{3}$ (D) \\ Received: 17 September 2019 / Accepted: 3 March 2020/Published online: 31 March 2020 \\ (C) Springer-Verlag GmbH Germany, part of Springer Nature 2020
}

\begin{abstract}
South Asians have a high prevalence of type 2 diabetes, even at a lower BMI. This review sets out our perspective and hypothesis on the reasons for this. Emerging data from epidemiological studies indicate that South Asians may have a lower ability to secrete insulin, and thus may have less compensatory reserves when challenged with unhealthy lifestyles. Thus, insulin resistance may not be the primary driver of type 2 diabetes in this population. Furthermore, data also suggest that South Asians, on average, have lower muscle mass, and may have a specific propensity to ectopic hepatic fat accumulation and for intramyocellular fat deposition, which cause further disruption in insulin action. We hypothesise that the high diabetes susceptibility in South Asians is evolutionarily set through dual parallel and/or interacting mechanisms: reduced beta cell function and impaired insulin action owing to low lean mass, which is further accentuated by ectopic fat deposition in the liver and muscle. These areas warrant further research.
\end{abstract}

Keywords Aetiology · Evolutionary biology $\cdot$ Hepatic fat · Insulin secretion $\cdot$ Lean muscle mass $\cdot$ Pathophysiology $\cdot$ Review South Asians · Type 2 diabetes

$\begin{array}{ll}\text { Abbreviations } \\ \text { CARRS } & \begin{array}{l}\text { Center for cArdiometabolic Risk Reduction in } \\ \text { CT }\end{array} \\ \text { South Asia } \\ \text { iIFG } & \text { Computed tomography } \\ & \text { Isolated impaired fasting glucose }\end{array}$

\section{Introduction}

South Asians (people living in, or with ancestry from, the Indian subcontinent), represent nearly 2 billion people

Electronic supplementary material The online version of this article (https://doi.org/10.1007/s00125-020-05132-5) contains a slide of the figure for download, which is available to authorised users.

K. M. Venkat Narayan

knaraya@emory.edu

1 Emory Global Diabetes Research Center, Hubert Department of Global Health, Rollins School of Public Health, Emory University, 1518 Clifton Road NE, CNR Room 7043, Atlanta, GA 30329, USA

2 Department of Medicine, School of Medicine, Emory University, Atlanta, GA, USA

3 Department of Medicine and Epidemiology and Biostatistics, University of California, San Francisco, CA, USA globally and have a high prevalence of type 2 diabetes, even at lower BMIs [1]. This increased diabetes risk among South Asians was first reported in the diaspora but has gathered greater attention as diabetes sweeps across South Asian countries, alongside economic development and dramatic changes in lifestyles [2]. Recent environmental changes, epidemiological transition and lifestyle changes (e.g. changes to diet and physical activity) are important in explaining the rise of type 2 diabetes in South Asians. However, given the high diabetes risk at low BMI in South Asians, the unique biological reasons driving the heightened risk of type 2 diabetes in South Asians compared with other ethnicities also need to be identified [3].

The often-cited biological reason for increased diabetes risk in South Asians is the propensity for insulin resistance, driven by higher visceral adiposity $[1,4,5]$. Much of this evidence placing obesity-driven insulin resistance as central to the pathophysiology of type 2 diabetes has come from studies in high-income well-nourished countries with an established obesity epidemic or from smaller replicative studies in South Asia. Furthermore, studies using objective measures of visceral adiposity have raised doubts about its unique or dominant role in the pathophysiology of type 2 diabetes in South Asians [6]. Thus, we may be overlooking 
potential differences in the pathophysiology and risk factors in the South Asian or other similar populations, especially in those who develop type 2 diabetes in the absence of obesity.

In this review, we will summarise recent longitudinal epidemiological data on diabetes incidence in South Asians. We acknowledge that diabetes risk in South Asians is a complex product of multiple factors, including genes, lifestyle, culture, socioeconomic factors and migration [1]. However, in this article, we focus selectively but critically on novel clues from studies of type 2 diabetes pathophysiology in South Asians placed in the context of intriguing historical knowledge from evolutionary biology studies in this population. We will emphasise three previously understudied areas investigating the high risk of type 2 diabetes in South Asians. We hypothesise that the high type 2 diabetes susceptibility in the South Asian population is evolutionarily set through dual parallel and/or interacting mechanisms: (1) reduced beta cell function and (2) impaired insulin action owing to low lean mass, which is further accentuated by (3) ectopic fat deposition in the liver and muscle (Fig. 1).

\section{Emerging epidemiological data on diabetes incidence in South Asian populations}

A few published studies on South Asians in the USA and Europe have indicated a higher incidence of type 2 diabetes in this population than in other ethnic groups [7, 8]. A recent study from Chennai, India, noted an alarmingly high incidence of prediabetes and diabetes ( 29.5 and 22.2 per 1000 person-years, respectively), and a possibly rapid conversion from prediabetes to diabetes [9]. Preliminary data from the largest populationbased cohort study in South Asians with follow-up data for multiple time points, the Center for cArdiometabolic Risk Reduction in South Asia (CARRS) [10], indicates that among urban people aged 20-44 years, the age-standardised diabetes incidence (cases/1000 person-years) in South Asians was 14.2
(95\% CI 12.2, 16.2) in men and 14.8 (95\% CI $13.0,16.5)$ in women. Furthermore, a recent analysis of diabetes incidence in South Asians compared with Pima Indians, a population reputedly with the world's highest diabetes incidence revealed some important findings [11]. Prospective analyses were done using data from two population-based cohorts of adults aged 2044 years: the Pima Indian Study (Pima Indians, $n=1852$ ), and CARRS (South Asians, $n=6676$ ). Diabetes was defined as fasting glucose $\geq 7.0 \mathrm{mmol} / \mathrm{l}(126 \mathrm{mg} / \mathrm{dl}), \mathrm{HbA}_{1 \mathrm{c}} \geq 6.5 \%$ (48 $\mathrm{mmol} / \mathrm{mol}$ ) or glucose-lowering medication use. At baseline, South Asians were less obese than Pima Indians (BMI: $24.4 \mathrm{vs} 33.8 \mathrm{~kg} / \mathrm{m}^{2}$; waist circumference: $82.5 \mathrm{vs} 107 \mathrm{~cm}$ ). Agestandardised diabetes incidence (cases/1000 person-years) was much lower in South Asians than in Pima Indians (men: 14.2 [95\% CI 12.2, 16.2] vs. 37.3 [95\% CI 31.8, 42.8; women: 14.8 $[13.0,16.5]$ vs 46.1 [41.2, 51.1]). However, among 20-44 year olds with a BMI $<25 \mathrm{~kg} / \mathrm{m}^{2}$, the incidence of diabetes in South Asian men was about fivefold that in South Asian men. Among those with a BMI $\geq 30 \mathrm{~kg} / \mathrm{m}^{2}$, diabetes incidence in South Asian men was nearly as high as in the Pima men [11].

Prospective cohort analyses in adults aged $\geq 45$ years compared the incidence of diabetes in South Asians, using data from the CARRS cohort $(n=3136)$, with that in white and black people in the US Atherosclerosis Risk in Communities Study (ARIC; black, $n=3059$; white, $n=$ 9924) [12]. Among those aged $\geq 45$ years, the agestandardised diabetes incidence in South Asian men and women was $26.0(95 \%$ CI 22.2, 29.8) and $31.9(95 \% \mathrm{CI}$ $27.5,36.2)$, respectively. In those with a BMI $<25 \mathrm{~kg} / \mathrm{m}^{2}$, the diabetes incidence in South Asian men and women was nearly 3 times and 5.3 times that in the corresponding sex in the white subgroup, respectively. Among those with a BMI $\geq 30 \mathrm{~kg} / \mathrm{m}^{2}$, the diabetes incidence in South Asian men and women was 2.6 and 2.1 times that in US white men and women, respectively [12]. Together, these data on incidence indicate that the South Asian population may have a higher risk of incident diabetes than other ethnic groups. This
Fig. 1 Proposed pathophysiological pathways for type 2 diabetes. Both impaired insulin secretion and impaired insulin action (or insulin resistance) have evolutionary roots among South Asians, with low beta cell function and low lean muscle mass. Adverse lifestyle behaviours further exacerbate insulin action with ectopic fat deposition in liver and muscle. This figure is available as a downloadable slide
Evolutionarily determined

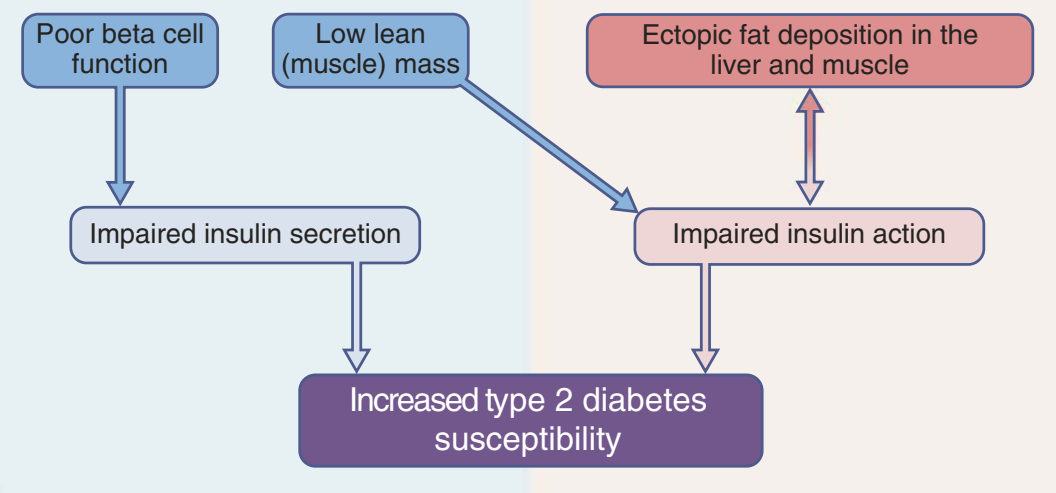


difference is particularly evident, even at low BMIs, suggesting that factors other than obesity and insulin resistance may be important to explore $[11,12]$.

\section{Pathophysiology}

Contextual knowledge from evolutionary biology South Asians, on average, have a low lean mass [13], which may confer specific susceptibility for diabetes. This may have historical roots. In a recent study of skeletons spanning the past 11,000 years, Pomeroy et al. investigated the ancient origins of low lean mass in the South Asian population [14]. They found that, compared with a worldwide sample, the skeletons of South Asians indicated low lean mass. The stature of South Asians decreased sharply when agriculture was adapted, while stature-adjusted lean mass increased to a minor extent over time. Pomeroy et al. concluded that the South Asian population has been characterised by low lean mass for thousands of years, and this phenomenon is unlikely to change in the short term. Historical data suggest that the South Asian population may have had good nutrition status in the Mesolithic period, as indicated by their relative tallness during that time [15]. However, since then, the population may have become increasingly undernourished for generations, and this may have become more pronounced during the period of British colonisation of the subcontinent [16]. These long-term intergenerational influences, especially those adversely affecting maternal and/or early childhood during the first 3 years of life, may have had an impact on the metabolic capacity of people in these populations [17], e.g. by leading to shorter stature, lower lean muscle mass, poorer organ development and increased diabetes susceptibility [18-20]. A number of studies also support the role of transgenerational metabolic pathways (e.g. poor insulin secretion, ectopic fat deposition and low lean mass) linking early malnourishment with diabetes risk $[21,22]$.

\section{Role of poor insulin secretion very early in the natural history} of diabetes There are reasons to consider South Asians as a population variant with higher frequencies of phenotypes of type 2 diabetes, wherein the primary problem may be poor insulin secretion (or impaired beta cell reserve) to start with [23-25]. A study comparing non-diabetic adult South Asians with Chinese Americans, Hispanics, African Americans and whites in the USA found that, in every age group, South Asians had the lowest insulin secretion, followed by Chinese Americans [3]. Studies of adults in India, youth-onset diabetes populations in India, and adult South Asians in the USA all point to the potential role of deficient insulin secretion in the early natural history of type 2 diabetes in South Asians [26-28]. Furthermore, in the Whitehall II cohort study in the UK, South Asians had a lower beta cell reserve relative to
Europids [29], and a study from the Netherlands suggested that family members of South Asians with type 2 diabetes may have poorer beta cell adaptation than family members of Dutch individuals, of European descent, with type 2 diabetes [30]. A comparison of Indians living in urban Chennai with Pima Indians in Arizona revealed that both populations have a roughly equal diabetes prevalence, despite the Chennai Indians being an average of $7 \mathrm{~kg} / \mathrm{m}^{2}$ lighter and having a waist circumference $25 \mathrm{~cm}$ smaller [31]. In addition, in all age groups, across weight and glucose categories (including those with normal BMI and normal glucose levels), the Pima Indians were two to four times more severely insulin resistant than the Chennai Indians and the Chennai Indians secreted a half to a third the amount of insulin compared with the Pima Indians. Notably, compared with Pima Indians, South Asians have relatively poorer insulin secretion at baseline and at 30 and $120 \mathrm{~min}$ after an oral glucose tolerance test. A limitation of these studies is that surrogate measures of insulin resistance and insulin secretion were used (e.g. HOMA-IR and HOMAB) rather than the gold standard measurements. One small study using hyperinsulinaemic-euglycaemic clamps found that South Asians, especially underweight or normal-weight individuals with metabolic abnormalities, did not have reduced insulin action, implying that reduced insulin secretion may need to be investigated in lean individuals at risk of developing type 2 diabetes [19].

Compared with other ethnic groups, South Asians have a higher prevalence of isolated impaired fasting glucose (iIFG), which is primarily the result of hepatic insulin resistance, with early phase, stationary impairment in beta cell function [32]. While the rate of conversion of prediabetes to diabetes in South Asians appears high (up to $14 \%$ per year), regardless of the prediabetes type, it is unclear whether those with iIFG have lower rates of conversion than those with isolated impaired glucose tolerance (iIGT), as few data on an adequate sample size exist $[9,33]$. In a lifestyle intervention followed by addition of metformin (when appropriate) among South Asians with prediabetes in Chennai, there was an overall relative risk reduction of $32 \%$ of progression to diabetes [33]. However, in the group with iIFG, the relative risk reduction was a non-significant $12 \%$. South Asians may also respond relatively less well to pharmacological agents, such as glitazones, that target insulin sensitivity (beta cell response to blood glucose) and/or insulin resistance (glucose uptake) [34]. Interventions that preserve or help recover beta cell function during the early normoglycaemic periods in South Asians need be researched, and possible strategies may include highintensity interval training or specific pharmacological approaches [35-37].

Role of abdominal visceral fat vs hepatic fat Greater body adiposity has been a theorised culprit for insulin resistance and type 2 diabetes among South Asians. Early studies from 
the UK reported that South Asians had a higher waist circumference compared with Europeans, supporting a role for central adiposity underpinning insulin resistance and its metabolic consequences. However, recent studies using computed tomography (CT) scans for ectopic fat measurements, including abdominal visceral fat and intrahepatic fat, have shown less consistent results [38-41]. A recent meta-analysis of published and unpublished studies with direct measures of visceral fat by $\mathrm{CT}$ or magnetic resonance imaging found no difference in abdominal visceral fat area among South Asian men and women compared with their white counterparts. However, there were consistently higher amounts of hepatic fat among South Asian compared with white individuals (Iliodromiti S, Queen Mary University, London, UK, personal communication).

This distinction between visceral fat and intrahepatic fat stores is important because of the different metabolic consequences at each site, with the liver being the prime organ for postprandial glucose metabolism and glycogen synthesis. An intriguing possibility to explain why South Asians have greater hepatic fat content than other groups is that the relatively higher saturated fat content of traditional South Asian diets may be involved [42]. In a short-term dietary trial of overfeeding saturated fat or polyunsaturated fat in normal-weight Swedish adults, while weight gain was similar in both the high-saturated-fat and high-polyunsaturated-fat groups, relatively higher amounts of hepatic fat than visceral fat were gained by the saturated fat group [43].

Few studies have measured both abdominal visceral fat and hepatic fat to determine their relative contributions to incident diabetes. In the Mediators of Atherosclerosis in South Asians Living in America (MASALA) study, abdominal visceral fat area and hepatic attenuation were independently associated with glycaemic progression (from normal, to impaired fasting glucose, to impaired glucose tolerance, to diabetes) [8]. Hepatic fat was more closely linked to progression from prediabetes to diabetes, indicating its role once dysglycaemia has already begun [9]. A recent Mendelian randomisation analysis of the UK Biobank data found that genetically predicted higher circulating liver enzymes, surrogate markers for nonalcoholic fatty liver disease, were associated with increased risk of type 2 diabetes [44]. Moreover, genetic variants associated with insulin resistance were also associated with these liver enzymes, indicating a causal relationship between insulin resistance resulting in fatty liver disease, which in turn increases type 2 diabetes risk [44].

Weight loss is a proven treatment for fatty liver, even among normal-weight Asians [45], and modest weight loss can decrease abdominal fat stores in general [46]. Several lifestyle modifications for non-alcoholic fatty liver disease (NAFLD) have been tested in short-term randomised trials in primarily non-Asian populations, showing that both hypoenergetic low-carbohydrate diets and low-fat diets, as well as isoenergetic (isocaloric) higher protein diets and diets high in fibre, can decrease intrahepatic lipid content [47]. In addition, aerobic, resistance and high-intensity interval training forms of exercise have each been shown to have similar effects on reducing hepatic fat, even independently of weight loss $[47,48]$. Culturally appropriate dietary and exercise interventions, with and without weight loss, focusing on hepatic steatosis are, therefore, needed for South Asians.

Role of skeletal muscle Low lean muscle mass is another important contributing factor that may promote susceptibility to diabetes among South Asians. Several studies have shown that South Asians have lower lean muscle mass than other race/ethnic groups [40, 41, 49]. As mentioned above, South Asians have exhibited low lean mass consistently over time, most likely representing long-term adaptation to climate or other more neutral variation [14]. Genetic studies of several populations from the South Asian subcontinent have found increased selection of a gene encoding myostatin [50], a protein that inhibits skeletal muscle growth in utero through poor placental glucose uptake. Lower lean muscle mass affects peripheral glucose uptake and clearance, since the skeletal muscle is responsible for metabolising $80 \%$ of circulating glucose [51]. Long-standing peripheral insulin resistance may further lead to earlier beta cell exhaustion [52], and may be especially important when insulin secretory reserves are already in short supply.

Another form of ectopic fat deposition, accumulation of lipids within the skeletal muscle from ineffective lipid metabolism as a result of dysfunctional mitochondrial oxidation, may also play a role in insulin resistance among South Asians. In a UK study comparing South Asians and Europids, South Asians had 30\% higher intramuscular triacylglycerols than BMI-matched Europids [53], and in a US study, South Asians had higher intermuscular fat on CT scans compared with other US race/ethnic groups [41]. While a build-up of intramyocellular lipids is not directly associated with insulin resistance [54], an accumulation of diacylglycerols and ceramides have molecular effects that may promote insulin resistance [55].

The role of the mitochondria in skeletal muscle in promoting insulin resistance remains heavily debated. The few studies investigating skeletal muscle mitochondrial function in South Asians have had conflicting results. In a small US study reported in 2008, among Asian Indians muscle oxidative capacity was similar for those with and without diabetes, and Asian Indians had a higher oxidative capacity than the white participants though the Asian Indians had more severe insulin resistance [56]. In an exercise study of 20 South Asian and 20 BMI-matched Europid men, the South Asian men had significantly more severe insulin resistance, had lower cardiorespiratory fitness and lower skeletal muscle fat oxidation with exercise, but this was not explained by genes known to be 
involved in fat oxidation and lipid metabolism [57]. Newer evidence refutes an impairment of mitochondrial capacity and posits a mitochondrial bioenergetics problem, with an oversupply of fuel that leads to mitochondrial reactive oxidation species production that impairs insulin signalling [58].

Lifestyle modification may directly affect lean muscle mass and mitochondrial function. In the Swedish overfeeding study mentioned above, the group assigned to polyunsaturated fat had a greater increase in lean muscle mass and no significant increase in other ectopic fat stores [43]. Dietary longchain saturated fatty acids impaired mitochondrial function while $n-3$ polyunsaturated fatty acids improved mitochondrial function [55]. Exercise training, both endurance and resistance exercise, can stimulate mitochondrial biogenesis and improve mitochondrial function and efficiency [59]. Few dietary or exercise interventions have been conducted among South Asians to determine the most beneficial diet or the most effective dose, type, intensity or duration of exercise to improve beta cell function, reduce ectopic fat stores or increase lean muscle mass [60] and thereby reduce diabetes risk in this population.

\section{Conclusion}

While data on type 2 diabetes prevalence have suggested that South Asians are at high risk, even at low BMI, recent data on diabetes incidence reviewed above further support this. Furthermore, these data on diabetes incidence also suggest that South Asians have a higher diabetes risk than other ethnic populations, and normal-weight South Asians have higher risk than normal-weight people of other ethnic groups, including white, black and Pima Indians. We postulate that the evolutionary history of the South Asians has endowed the population with significant susceptibility to type 2 diabetes through a dual mechanism (Fig. 1). Our hypothesis is that this susceptibility is primarily driven by poor metabolic capacity (i.e. reduced beta cell mass and/or function, which impairs insulin secretion) coupled with low lean muscle mass, which may be responsible for reduced insulin action. This is accentuated by a propensity to ectopic fat deposition in the liver and muscle, which further impairs insulin action. These unique evolutionary and anthropomorphic features of South Asians, relative to other ethnic groups, will need to be considered to formulate an innovative research agenda for solving the problem. Wellsupported programmes of interdisciplinary research, spanning basic/translational sciences, longitudinal epidemiology and intervention studies are needed, with robust measures of insulin secretion, lean mass, hepatic fat and glucose patterns, in South Asian populations in host countries and in the diaspora. There is also an urgent need to unravel the basic biological reasons (e.g. poor insulin secretion, low lean mass, hepatic steatosis, myosteatosis, mitochondrial metabolism) that put
South Asians at such high risk for diabetes, through highquality basic science research. Simultaneously, research into potential clinical and public health interventions to address these specific susceptibilities in South Asians, using robust measurements and appropriate endpoints, are needed. Among them are behavioural and pharmacological strategies to improve beta cell preservation and/or approaches to improve lean mass and reduce ectopic fat deposition.

Acknowledgements We thank U. Gujral and L. Staimez (Hubert Department of Global Health, Rollins School of Public Health, Emory University) for their critical comments on this manuscript.

Funding KMVN's research cited in this manuscript was funded in part by the National Heart, Lung, and Blood Institute (NHLBI), National Institutes of Health (NIH), Department of Health and Human Services (under contract no. HHSN268200900026C) and the United Health Group (Minneapolis, MN, USA). KMVN was also supported in part by the NIH/ NHLBI (award number R01HL125442) and by the NIH National Institute of Diabetes And Digestive And Kidney Diseases (NIDDK; award number P30DK111024). Work by AMK is supported by grants from the NIH/NHLBI (award numbers 2R01HL093009 and 2 K24HL112827) and by the NIH/NIDDK (award numbers P30DK098722 and 2P30K092924). The content is solely the responsibility of the authors and does not necessarily represent the official views of the NIH.

Authors' relationships and activities The authors declare that there are no relationships or activities that might bias, or be perceived to bias, their work.

Contribution statement Both authors were responsible for drafting the article and revising it critically for important intellectual content. Both authors approved the version to be published.

\section{References}

1. Gujral UP, Pradeepa R, Weber MB, Narayan KM, Mohan V (2013) Type 2 diabetes in South Asians: similarities and differences with white Caucasian and other populations. Ann N Y Acad Sci 1281: 51-63. https://doi.org/10.1111/j.1749-6632.2012.06838.x

2. Unnikrishnan R, Gupta PK, Mohan V (2018) Diabetes in South Asians: phenotype, clinical presentation, and natural history. Curr Diab Rep 18(6):30. https://doi.org/10.1007/s11892-018-1002-8

3. Kanaya AM, Herrington D, Vittinghoff E et al (2014) Understanding the high prevalence of diabetes in U.S. south Asians compared with four racial/ethnic groups: the MASALA and MESA studies. Diabetes Care 37(6):1621-1628. https://doi. org/10.2337/dc13-2656

4. Chandalia M, Lin P, Seenivasan T et al (2007) Insulin resistance and body fat distribution in South Asian men compared to Caucasian men. PLoS One 2(8):e812. https://doi.org/10.1371/journal.pone. 0000812

5. Banerji MA, Faridi N, Atluri R, Chaiken RL, Lebovitz HE (1999) Body composition, visceral fat, leptin, and insulin resistance in Asian Indian men. J Clin Endocrinol Metab 84(1):137-144. https://doi.org/10.1210/jcem.84.1.5371

6. Gujral UP, Vittinghoff E, Mongraw-Chaffin M et al (2017) Cardiometabolic abnormalities among normal weight individuals from five race/ethnic groups in the United States: cross-sectional analysis 
from two cohort studies. Ann Intern Med 166(9):628-636. https:// doi.org/10.7326/M16-1895

7. Karter AJ, Schillinger D, Adams AS, Moffet HH, Liu J, Adler NE, Kanaya AM (2013) Elevated rates of diabetes in Pacific islanders and Asian subgroups: the diabetes study of northern California (DISTANCE). Diabetes Care 36(3):574-579. https://doi.org/10. 2337/dc12-0722

8. Gujral U, Narayan KMV, Kandula NR, Liu K, Kanaya AM (2019) Incidence and predictors of diabetes and prediabetes among south Asians in the United States: the MASALA study. Diabetes 68(Suppl 1):1636 (Abstract)

9. Anjana RM, Shanthi Rani CS, Deepa M et al (2015) Incidence of diabetes and prediabetes and predictors of progression among Asian Indians: 10-year follow-up of the Chennai urban rural epidemiology study (CURES). Diabetes Care 38(8):1441-1448. https:// doi.org/10.2337/dc14-2814

10. Nair M, Ali MK, Ajay VS et al (2012) CARRS surveillance study: design and methods to assess burdens from multiple perspectives. BMC Public Health 12(1):701. https://doi.org/10.1186/1471-245812-701

11. Narayan KMV, Kondal D, Kobes S et al (2019) Incidence of diabetes in young adult South Asians compared with Pima Indians. Diabetes 68(Suppl 1):1597 (Abstract)

12. Narayan KMV, Kondal D, Daya NR et al (2019) Incidence of diabetes in south Asian adults in urban India/Pakistan compared with blacks and whites in U.S. Diabetes 68(Suppl 1):1598 (Abstract)

13. Haroun D, Taylor SJ, Viner RM et al (2010) Validation of bioelectrical impedance analysis in adolescents across different ethnic groups. Obesity (Silver Spring) 18(6):1252-1259. https://doi.org/ 10.1038/oby.2009.344

14. Pomeroy E, Mushrif-Tripathy V, Cole TJ, Wells JCK, Stock JT (2019) Ancient origins of low lean mass among South Asians and implications for modern type 2 diabetes susceptibility. Sci Rep 9(1): 10515. https://doi.org/10.1038/s41598-019-46960-9

15. Lukacs JR, Pal JN (2003) Skeletal variation among Mesolithic people of the Ganga Plains: new evidence of habitual activity and adaptation to climate. Asian Perspect 42(2):329-351. https://doi. org/10.1353/asi.2003.0042

16. Wells JC, Pomeroy E, Walimbe SR, Popkin BM, Yajnik CS (2016) The elevated susceptibility to diabetes in India: an evolutionary perspective. Front Public Health 4:145

17. Victora CG, de Onis M, Hallal PC, Blossner M, Shrimpton R (2010) Worldwide timing of growth faltering: revisiting implications for interventions. Pediatrics 125(3):e473-e480. https://doi. org/10.1542/peds.2009-1519

18. de la Grandmaison GL, Clairand I, Durigon M (2001) Organ weight in 684 adult autopsies: new tables for a Caucasoid population. Forensic Sci Int 119(2):149-154. https://doi.org/10.1016/s03790738(00)00401-1

19. Thomas N, Grunnet LG, Poulsen P et al (2012) Born with low birth weight in rural southern India: what are the metabolic consequences 20 years later? Eur J Endocrinol 166(4):647-655. https://doi.org/ 10.1530/EJE-11-0870

20. Kohli A, Aggarwal N (2006) Normal organ weights in Indian adults. Medico-Legal Update 6(2):49-52

21. Hanafi MY, Saleh MM, Saad MI, Abdelkhalek TM, Kamel MA (2016) Transgenerational effects of obesity and malnourishment on diabetes risk in F2 generation. Mol Cell Biochem 412(1-2):269280. https://doi.org/10.1007/s11010-015-2633-6

22. Group B-GSW, Huang T, Wang T et al (2019) Association of birth weight with type 2 diabetes and glycemic traits: a Mendelian randomization study. JAMA Netw Open 2(9):e1910915

23. Narayan KM (2016) Type 2 diabetes: why we are winning the battle but losing the war? 2015 Kelly West Award Lecture. Diabetes Care 39(5):653-663. https://doi.org/10.2337/dc16-0205
24. Hulman A, Gujral UP, Narayan KMV et al (2017) Glucose patterns during the OGTT and risk of future diabetes in an urban Indian population: the CARRS study. Diabetes Res Clin Pract 126:192197. https://doi.org/10.1016/j.diabres.2017.01.009

25. Ahlqvist E, Storm P, Karajamaki A et al (2018) Novel subgroups of adult-onset diabetes and their association with outcomes: a datadriven cluster analysis of six variables. Lancet Diabetes Endocrinol 6(5):361-369. https://doi.org/10.1016/S2213-8587(18) 30051-2

26. Staimez LR, Weber MB, Ranjani H et al (2013) Evidence of reduced beta-cell function in Asian Indians with mild dysglycemia. Diabetes Care 36(9):2772-2778. https://doi.org/10.2337/dc122290

27. Mohan V, Amutha A, Ranjani H et al (2013) Associations of betacell function and insulin resistance with youth-onset type 2 diabetes and prediabetes among Asian Indians. Diabetes Technol Ther 15(4):315-322. https://doi.org/10.1089/dia.2012.0259

28. Gujral UP, Narayan KM, Kahn SE, Kanaya AM (2014) The relative associations of beta-cell function and insulin sensitivity with glycemic status and incident glycemic progression in migrant Asian Indians in the United States: the MASALA study. J Diabetes Complicat 28(1):45-50. https://doi.org/10.1016/j.jdiacomp.2013. 10.002

29. Ikehara S, Tabak AG, Akbaraly TN et al (2015) Age trajectories of glycaemic traits in non-diabetic South Asian and white individuals: the Whitehall II cohort study. Diabetologia 58(3):534-542. https:// doi.org/10.1007/s00125-014-3448-9

30. Jainandunsing S, Ozcan B, Rietveld T et al (2015) Failing beta-cell adaptation in South Asian families with a high risk of type 2 diabetes. Acta Diabetol 52(1):11-19. https://doi.org/10.1007/s00592014-0588-9

31. Staimez LR, Deepa M, Ali MK, Mohan V, Hanson RL, Narayan KMV (2019) Tale of two Indians: heterogeneity in type 2 diabetes pathophysiology. Diabetes Metab Res Rev 35(8):e3192

32. Abdul-Ghani MA, Tripathy D, DeFronzo RA (2006) Contributions of beta-cell dysfunction and insulin resistance to the pathogenesis of impaired glucose tolerance and impaired fasting glucose. Diabetes Care 29(5):1130-1139. https://doi.org/10.2337/diacare.2951130

33. Weber MB, Ranjani H, Staimez LR et al (2016) The stepwise approach to diabetes prevention: results from the D-CLIP randomized controlled trial. Diabetes Care 39(10):1760-1767. https://doi. org $10.2337 / \mathrm{dc} 16-1241$

34. Boyko EJ, Gerstein HC, Mohan V et al (2010) Effects of ethnicity on diabetes incidence and prevention: results of the Diabetes REduction Assessment with ramipril and rosiglitazone Medication (DREAM) trial. Diabet Med 27(11):1226-1232. https://doi.org/10.1111/j.1464-5491.2010.03064.x

35. van Raalte DH, Verchere CB (2017) Improving glycaemic control in type 2 diabetes: stimulate insulin secretion or provide beta-cell rest? Diabetes Obes Metab 19(9):1205-1213. https://doi.org/10. 1111/dom.12935

36. Babraj JA, Vollaard NB, Keast C, Guppy FM, Cottrell G, Timmons JA (2009) Extremely short duration high intensity interval training substantially improves insulin action in young healthy males. BMC Endocr Disord 9(1):3. https://doi.org/10.1186/1472-6823-9-3

37. Madsen SM, Thorup AC, Overgaard K, Jeppesen PB (2015) High intensity interval training improves glycaemic control and pancreatic beta cell function of type 2 diabetes patients. PLoS One 10(8): e0133286. https://doi.org/10.1371/journal.pone.0133286

38. Lear SA, Humphries KH, Kohli S, Chockalingam A, Frohlich JJ, Birmingham CL (2007) Visceral adipose tissue accumulation differs according to ethnic background: results of the Multicultural Community Health Assessment Trial (M-CHAT). Am J Clin Nutr 86(2):353-359. https://doi.org/10.1093/ajcn/86.2. 353 
39. Eastwood SV, Tillin T, Wright A et al (2013) Estimation of CTderived abdominal visceral and subcutaneous adipose tissue depots from anthropometry in Europeans, South Asians and African Caribbeans. PLoS One 8(9):e75085. https://doi.org/10.1371/ journal.pone. 0075085

40. Eastwood SV, Tillin T, Wright A et al (2014) Thigh fat and muscle each contribute to excess cardiometabolic risk in South Asians, independent of visceral adipose tissue. Obesity (Silver Spring) 22(9):2071-2079. https://doi.org/10.1002/oby.20796

41. Shah AD, Kandula NR, Lin F et al (2016) Less favorable body composition and adipokines in South Asians compared with other US ethnic groups: results from the MASALA and MESA studies. Int J Obes 40(4):639-645. https://doi.org/10.1038/ijo.2015.219

42. Misra A, Khurana L, Isharwal S, Bhardwaj S (2009) South Asian diets and insulin resistance. Br J Nutr 101:465-473

43. Rosqvist F, Iggman D, Kullberg J et al (2014) Overfeeding polyunsaturated and saturated fat causes distinct effects on liver and visceral fat accumulation in humans. Diabetes 63(7):2356-2368. https:// doi.org/10.2337/db13-1622

44. De Silva NMG, Borges MC, Hingorani AE et al (2019) Liver function and risk of type 2 diabetes: bidirectional Mendelian randomization study. Diabetes 68(8):1681-1691. https://doi.org/10.2337/ db18-1048

45. Chooi YC, Ding C, Chan Z et al (2018) Moderate weight loss improves body composition and metabolic function in metabolically unhealthy lean subjects. Obesity (Silver Spring) 26(6):10001007. https://doi.org/10.1002/oby.22185

46. Fujimoto WY, Jablonski KA, Bray GA et al (2007) Body size and shape changes and the risk of diabetes in the diabetes prevention program. Diabetes 56(6):1680-1685. https://doi.org/10.2337/db070009

47. El-Agroudy NN, Kurzbach A, Rodionov RN et al (2019) Are lifestyle therapies effective for NAFLD treatment? Trends Endocrinol Metab 30(10):701-709. https://doi.org/10.1016/j.tem.2019.07.013

48. Sabag A, Way KL, Keating SE et al (2017) Exercise and ectopic fat in type 2 diabetes: a systematic review and meta-analysis. Diabetes Metab 43(3):195-210. https://doi.org/10.1016/j.diabet.2016.12. 006

49. Rush EC, Freitas I, Plank LD (2009) Body size, body composition and fat distribution: comparative analysis of European, Maori, Pacific Island and Asian Indian adults. Br J Nutr 102(4):632-641. https://doi.org/10.1017/S0007114508207221

50. Metspalu M, Romero IG, Yunusbayev B et al (2011) Shared and unique components of human population structure and genome- wide signals of positive selection in South Asia. Am J Hum Genet 89(6):731-744. https://doi.org/10.1016/j.ajhg.2011.11.010

51. Shulman GI, Rothman DL, Jue T, Stein P, DeFronzo RA, Shulman RG (1990) Quantitation of muscle glycogen synthesis in normal subjects and subjects with non-insulin-dependent diabetes by ${ }^{13} \mathrm{C}$ nuclear magnetic resonance spectroscopy. N Engl J Med 322(4): 223-228. https://doi.org/10.1056/NEJM199001253220403

52. DeFronzo RA, Bonadonna RC, Ferrannini E (1992) Pathogenesis of NIDDM. A balanced overview. Diabetes Care 15(3):318-368. https://doi.org/10.2337/diacare.15.3.318

53. Forouhi NG, Jenkinson G, Thomas EL et al (1999) Relation of triglyceride stores in skeletal muscle cells to central obesity and insulin sensitivity in European and South Asian men. Diabetologia 42(8): 932-935. https://doi.org/10.1007/s001250051250

54. Goodpaster BH, He J, Watkins S, Kelley DE (2001) Skeletal muscle lipid content and insulin resistance: evidence for a paradox in endurance-trained athletes. J Clin Endocrinol Metab 86(12): 5755-5761. https://doi.org/10.1210/jcem.86.12.8075

55. Sergi D, Naumovski N, Heilbronn LK et al (2019) Mitochondrial (dys)function and insulin resistance: from pathophysiological molecular mechanisms to the impact of diet. Front Physiol 10: 532. https://doi.org/10.3389/fphys.2019.00532

56. Nair KS, Bigelow ML, Asmann YW et al (2008) Asian Indians have enhanced skeletal muscle mitochondrial capacity to produce ATP in association with severe insulin resistance. Diabetes 57(5): 1166-1175. https://doi.org/10.2337/db07-1556

57. Hall LM, Moran CN, Milne GR et al (2010) Fat oxidation, fitness and skeletal muscle expression of oxidative/lipid metabolism genes in South Asians: implications for insulin resistance? PLoS One 5(12):e14197. https://doi.org/10.1371/journal.pone.0014197

58. Cade WT (2018) The manifold role of the mitochondria in skeletal muscle insulin resistance. Curr Opin Clin Nutr Metab Care 21(4): 267-272. https://doi.org/10.1097/MCO.0000000000000480

59. Distefano G, Goodpaster BH (2018) Effects of Exercise and aging on skeletal muscle. Cold Spring Harb Perspect Med 8(3). https:// doi.org/10.1101/cshperspect.a029785

60. Muilwijk M, Nicolaou M, Qureshi SA et al (2018) Dietary and physical activity recommendations to prevent type 2 diabetes in South Asian adults: a systematic review. PLoS One 13(7): e0200681. https://doi.org/10.1371/journal.pone.0200681

Publisher's note Springer Nature remains neutral with regard to jurisdictional claims in published maps and institutional affiliations. 